\title{
La introducción del vapor en el sistema colonial español de comunicaciones marítimas: 1848-1850
}

\author{
FRANCISCO PINIELLA CORBACHO
}

\section{ANTECEDENTES DE LA PROPULSION NAVAL NO-EOLICA: LA INTRODUCCION DEL BUQUE A VAPOR EN LAS PRIMERAS LINEAS DE CABOTAJE}

Hasta la conjunción final del elemento propulsor helicoidal y el agente motor vapor, se desarrollaron diferentes combinaciones que giraban fundamentalmente en torno al desarrollo de la rueda de paletas y al uso de agentes motores animados mediante el esfuerzo humano o animal (1). Sirva ello para justificar un aspecto no abordado, al menos suficientemente, por la bibliografía general sobre los buques a vapor. Y es que cuando se aplica la máquina de vapor a los buques, esta es posible gracias a un desarrollo previo del elemento propulsor de paletas, basado en la tecnología de los molinos de viento. Las primeras máquinas de vapor, el agente motor que se impondrá por primera vez en los buques de forma experimental en los primeros añ்os del siglo XIX, ya se conocían en tierra en el S.XVII (Branca, Huyghens, Papin, Savery...), con utilidades como el achique de agua para las minas de Inglaterra (2). Como bien es sabido, el escocés James Watt en 1764 proporciona un importante avance en el desarrollo de la máquina de vapor cambiando el principio motor de la máquina atmósférica por el de máquina de presión de vapor propiamente dicha, primero de simple efecto, y posteriormente de doble efecto (émbolo ascendente y descendente). Fue la máquina de Watt la primera en aplicarse con cierto éxito a los buques fluviales, a una y otra orilla: en el Sena, Perrier en 1775, en el Saona (Lyon), Jouffroy d'Abbans en 1784, en el Delaware, John Fitch en 1787, etc. Así hasta que Robert Fulton, norteamericano trasladado a Inglaterra y Francia, logra construir el "Nautilus" y el "Clermont", con una aplicación práctica del vapor a la navegación. La primera experiencia española de uso comercial del buque a vapor, aunque temprana, en 1817, fue poco exitosa debido

(1) Cfr. HERNÁANDEZ MOLINA, R. "Antecedentes Históricos de la Propulsión Mecánica" Espai/Temps - Quaderns del Departament de Geografia i Història de l'Estudi General de Lleida. Lérida, 1992.

(2) Cfr: CASANUEVA GONZALEZ, F. Elementos para una bistoria de la navegación a vapor. Cádiz, 1990. Tesis inédita. Departamento de Historia Moderna, Contemporánea, América y del Arte. Universidad de Cádiz. 
a las numerosas averías. Se trataba del "Real Fernando", alias Betis, construido para el servicio del Río Guadalquivir hasta Sanlúcar y Cádiz en los astilleros de Triana aunque la máquina procedía integramente de Inglaterra (Talleres Boulton y Watt). El barco tenía unas dimensiones de 21,43 metros de eslora, 6,81 metros de manga máxima (incluída las ruedas de palas laterales), 3,65 metros de manga del casco y 1,82 metros de puntal, una capacidad máxima de trece tripulantes, sesenta y cinco pasajeros en cámaras, ocho en camarotes y cuarenta en cubierta (3).

En Cuba las primeras noticias de buques con máquinas a vapor la encontramos en el año de 1822, en un escrito dirigido por Domingo Nadam, canario residente en Matanzas, para registrar de acuerdo con la ley de inventos y patentes un buque a vapor de cuarenta toneladas, para la comunicación fluvial del Río Canimar, desde su parte alta hasta la desembocadura en la Bahía de Matanzas (4). En 1834 se establecieron también los vapores-correos entre Matanzas y La Habana con el objeto de trasladar la correspondencia entre ambos puntos (5). Y en 1840 ya existía otra línea de vapores locales, que partiendo desde La Habana llegaba a Batabanó, Cienfuegos, Trinidad, Santa Cruz, Manzanillo y Santiago (6).

\section{LA INCORPORACION DEL BUQUE A VAPOR EN LAS LINEAS DE CORREOS}

La primera utilización del buque a vapor para el transporte de correspondencia se realizó en el Canal de La Mancha en 1826 con una compañía inglesa de cinco vapores (7). Los ingleses establecieron en 1835 el buque a vapor en la comunicación postal (el "Liverpool" y el "William Fawcett") entre la Metrópoli y Gibraltar: los buques salían de Londres, Falmouth, Oporto, Lisboa, Cádiz y Gibral$\operatorname{tar}(8)$. Esta línea se extendería un año después a Vigo y Madeira con la Compañía Peninsular de Vapores de S.M. Británica (9). Pero las primeras líneas trasatlánticas, exclusivamente a vapor, tardarían unos cuantos años en llegar, pues hasta el año 1838 no se cruzó por primera vez el Atlántico con el buque "Sirius" (10). Ese mismo año se constituyó la primera compañía de vapores que obtuvo la concesión del Correo Marítimo entre Inglaterra y los EE.UU., se trataba de la Cunard Line con cuatro unidades de algo más de dos mil toneladas: el "Britannic", "Acadia", "Caledonia", y "Columbia".

(3) ALEMANY LLOVERA, J. "La revolución del vapor" Navegación (Catálogo del Pabellón Temático EXPO'92). Sevilla, 1992. p. 167.

(4) Registro de Patente de Don Domingo Nadam. Matanzas 1822. Archivo Nacional de Cuba (A.N.C.), Sección Reales Ordenes y Cédulas, Legajo 69, Documento 1.

(5) Informe del Administrador de Correos de La Habana al Director General del Ramo. La Habana, 30 de Septiembre de 1834. Archivo General de Indias (A.G.I.) Ultramar, 298.

(6) Anuncios de estas líneas en: Diario de la Habana. La Habana, 25 de Febrero de 1840. y en Noticioso y Lucero. La Habana, 26 de Febrero de 1840. La Habana, 26 de Febrero de 1840. A.N.C.

(7) PONTY, V. Historia de las Comunicaciones: Transportes Maritimos. Pamplona, 1965. Salvat. p. 103.

(8) Parte Oficial de Vigia. Cádiz, 2 de Octubre de 1835. Biblioteca de Temas Gaditanos (B.T.G.)

(9) Parte Oficial de Vigia. Câdiz, 12 de Diciembre de 1836. B.T.G.

(10) Con anterioridad lo había hecho el "Savannah" en 1819 pero utilizando el vapor como motor auxiliar a la vela. Vid. BROSSARD, M. Historia Marítima del Mundo. Barcelona, 1976. Amaika. Tomo II, p. 208. 
La Royal Mail Steampacket Company comienza a extenderse por todo el mundo," lo que llevará consigo la reforma del sistema postal británico, cuya influencia se dejó sentir incluso en las comunicaciones entre España y Ultramar: Puerto Rico, La Habana y Santiago se convirtieron en puntos de distribución de la correspondencia inglesa en el Caribe (11). Las Agencias Postales Inglesas, estuvieron vigentes hasta la incorporación de Cuba como colonia española en la Unión Postal Universal (1877). Los paquebotes ingleses en la Isla de Cuba habían tenido tradicionalmente un trato preferente, así los buques correos ingleses que tenían línea regular con Jamaica repartian la correspondencia en La Habana con un porte moderado y los capitanes podían entregar la correspondencia directamente a los comisionados británicos, punto éste que fue suprimido cuando las relaciones políticas no fueron suficientemente fluidas (12). No resulta extraño, por tanto, que los nuevos vapores ingleses intentaran recibir exenciones fiscales como no pagar derechos de puerto cuando los buques sólo realizaban cometidos postales o! de transporte de pasajeros, limitaciones en los derechos de importación-exportación para efectos inferiores a las 3 Tons. y otros beneficios de caracter fiscal (13). En los primeros años del servicio existieron problemas, que obedecían más a las desavenencias del Cónsul inglés en la Isla, Mr Turnbull con los Administradores de Correos, pues una vez que éste fue sustituido por $\mathrm{Mr}$ Crawford, el sistema de Agencias Postales inglesas se estableció definitivamente en la Isla. Para Guerra Aguiar, Turnbull pretendía hacerse con el sistema postal en La Habana para así poder controlar sin intervención cubana la correspondencia de la Sociedad Antiesclavista de Londres (14) (15).

Esta expansión de la nueva tecnología se realiza también por Oriente, así en el cuarenta y tres se establece en Gibraltar la línea con la India por buque a vapor. El "Bentick", de mil ochocientas toneladas, realizará la travesía invirtiendo no más de sesenta días, haciendo escala en Cabo de Buena Esperanza, Mauricio, Ceylan y Madrás. De esta forma el comerciante gaditano puede utilizar los servicios postales via-vapor-Gibraltar hasta la propia India (16).

(11) GUERRA AGULAR, J.L. Historia Postal de Cuba. Madrid, 1983. Laiz. p. 85

(12) Privilegios del Servicio de Paquetes de S.M. Británica a Jamaica en su escala en La Habana. 1829. A.N.C. Reales Ordenes y Cédulas, 78 (155).

(13) Real Orden sobre exenciones fiscales a las Malas Inglesas. Madrid, 25 de Agosto de 1841. A.N.C. Intendencia, 306 (81).

(14) GUERRA AGULAR, J.L. Op. cit. (Historia Postal de Cuba) p. 85.

(15) En diferentes puertos españoles, como la Coruña o Cádiz, aparecerían reclamos publicitarios como los publicados en el Parte Oficial de Vigía de Cádiz, del 28 de Diciembre de 1841. (B.T.G.): ANUNCIO. La dirección de la compañía Real, para el despacho de Correos-Vapores a las Indias Occidentales y América, previene al público, que cada quince días principiando desde el primero de Enero de 1842, saldrá de Southampton un vapor de 1.400 Toneladas y de la potencia de 450 caballos, conduciendo la correspondencia de S.M.B. a la Isla de la Barbada, a donde otras fragatas de vapor de iguales dimensiones y fuerzas, estarán esperando su llegada, para llevar las malas y pasageros a todas las Antillas, tanto Británicas como estrangeras, y a todos los puertos principales de la tierra firme desde Surinam hasta Chagre, también a Honduras, Habana, New Orleans, Tampico y Veracruz. Informará sobre el precio de flete o de pasage a los diferentes puntos indicados D. Pedro del Corral y Puente, caile Ancha $n^{9} 139$.

(16) Pa1te Oficial de Vigía. Cádiz, 19 de Agosto de 1843. B.T.G. 
Mientras tanto en España se van estableciendo algunas líneas, cubiertas con buques a vapor, todavía de cabotaje, como la Empresa Cántabra de Buques de Vapor, con base en Cádiz, encargada de realizar la travesía con el Norte de España y prolongación hasta Burdeos con el "Primer Coruñés" (17). En el Puerto de Cádiz, en el movimiento anual de buques en el año 1850, los vapores ocupaban ya un escalón significativo como puede verse en el Gráfico 1 (18), de procedencia española e inglesa principalmente (Gráfico 2). Puede ser significativa la creación de una Compañía Española de Vapores Marítimos en 1847 (19), que no llega a adquirir ningún barco ultramarino con tal denominación.

Definitivamente, el asunto de los vapores en España como en el resto del mundo, fue debatido bajo un prisma económico. No se trataba de un barco rentable ya que el consumo de carbón eran tan enorme que no se disponía de espacio de bodega suficiente como para que la inversión fuera rentable, además de los problemas que traía la incorporación de toda nueva tecnología, como el personal especializado extranjero al que había que recurrir, etc. No es de extrañar que Inglaterra fuera la nación pionera en el establecimiento de vapores. Para Inglaterra era una necesidad que se podía costear ya fuese a través de vapores estatales o por subvenciones indirectas como el transporte de correspondencia.

En la correspondecia del Capitan General de Cuba con Madrid encontramos ya, en Enero de 1847, una primera alusión al respecto de la llegada a la Isla de los primeros vapores ingleses:

"Este ventajoso proyecto [se refiere a los buques vapores] era irrealizable por cuenta del Estado, por no encontrarse el Erario público en situación de sostener los gastos inmensos (...) Francia que había concebido igual proyecto con anticipación, hechos los gastos de compra y construcción de buques, había tenido que desistir al primer ensayo, continuando unicamente la Inglaterra en mantener su línea de vapores trasatlánticos por minas de política y de comercio, pero sufriendo considerables pérdidas" (20).

\section{EL PRIMER PROYECTO ESPAÑOL PARA LA CONSTRUCCION DEL PRIMER CORREO A VAPOR}

El sistema colonial de Comunicaciones Marítimas en la primera mitad del Siglo XIX, había sido hasta entonces un fiel reflejo de la decadencia progresiva del Estado, podemos decir que tras el fracaso dieciochesco de los Correos Marítimos materializado en la Paz de Amiens de 1802, el Gobierno de Madrid había renunciado al mantenimiento propio de un servicio marítimo regular con lo que

(17) Parte Oficial de Vigía. Cádiz, 27 de Marzo, 19 de Abril y 7 de Junio de 1842. B.T.G.

(18) No se han incluido en esta relación los servicios tegulares de pequeños vapores como los que operaban con Sevilla.

(19) Creada por Real Orden de 30 de Enero de 1847. Vid. Carta de Don José de Orive, Presidente de la Compañia Española de Vapores Maritimos a S.M. Madrid, 24 de Julio de 1847. A.G.I. Ultramar, 854.

(20) Acta de la Junta de Autoridades de la Isla de Cuba. La Habana, 8 de Junio de 1844. A.G.I. Ultramar, 854. 
quedaba de su Imperio Colonial. La Metrópoli, imposibilitada económicamente, había tenido que sucumbir en su propósito de correo estatal ante un sistema privado de correos marítimos: la Empresa Mercantil de Correos Marítimos, gestionada desde La Habana como sociedad de acciones desde 1827 hasta 1847. En ese año, 1847, la Empresa de Correos cambia de titularidad: es adquirida por un Banco, el Banco Español de Ultramar, que posteriormente se fusionará con otras entidades creando el Banco de Fomento y de Ultramar. El Estado, a su vez, en una situación de fuerza al adquirir en estas fechas la Armada Nacional, tres buques a vapor (21), renegocia la Contrata que inicialmente había firmado con Manuel Villota, representante de la nueva Empresa en Madrid.

Las nuevas bases del contrato con el Banco incluyen catorce puntos de actuación, que varían considerablemente en el sentido cualitativo de la operación:

"1 El Banco Español de Ultramar se obliga a montar una línea de vapores que alternando con los buques de vela hagan el servicio de Correos de Cádiz a La Habana y viceversa.

$2^{o}$. El Banco tendrá a lo menos dos buques de vapor de la fuerza cada uno al menos de trescientos caballos, y cuatro buques de vela del porte de trescientas toneladas para arriba.

$3^{0}$ La construcción de estos buques será la propia y adecuada para los usos de la marina militar; de manera que en caso de necesidad, (...) puedan ser artillados con arreglo al porte de cada uno.

$4^{0}$ Por el Ministerio de Marina se nombrará uno o más constructores u otros Oficiales facultativos que examinen los buques y certifiquen.

$5^{\circ}$. Los buques mencionados harán al menos catorce viages redondos en cada año.

60 El Gobierno puede, en caso de guerra o en cualquier otro en que le conviniere, disponer de los buques-correos, previa la competente indemnización.

$7^{\circ}$ El Banco Español de Ultramar comenzará precisamente a hacer el servicio con los vapores en el término de un año a contar desde esta fecha.

$8^{0}$ 'La Empresa tendrá obligación de mantener a bordo y enseñar a su costa para maquinistas a dos alumnos en cada buque de vapor (...).

9o El Gobierno se reserva la facultad de hacer con los buques de la Marina Real este servicio si así le conviniere, indemnizando previamente a la Empresa, avisando con dos años de anticipación. La indemnización será la compra de los buques de la Empresa a justa tasación por peritos nombrados por ambas partes.

$10^{\circ}$ Para recompensar los sacrificios que el establecimiento de los vapores ha de causar a la Empresa, se amplia quince años la duración del Convenio que había fijado en diez la R.O. de 18 de Febrero próximo.

$11^{\varrho}$ A la terminación de este contrato el Gobierno comprará a la Empresa los buques que puedan convenirle por estar en buen estado de servicio. (...)

(21) En 1846 la Marina de Guerra compra a la de Mexico tres vapores: el "Castilla", "León" y "Satélite". Vid. GARAY UNIBASO, F. Correos Maritimos Españoles, Bilbao 1987, Edit. Mensajero, Tomo II, p. 119. 
$12^{\circ}$ Peritos nombrados por ambas partes fijarán el precio a los buques declarados en buen estado por los delegados del Gobierno.

$13^{\circ}$ En todos los puntos donde hagan escala los vapores señalará el Gobierno el muelle en que han de atracar para recibir el combustible con la perentoriedad que reclama este servicio.

$14^{\circ}$ En cuanto no se oponga a estas disposiciones, quedan en su fuerza y vigor las contenidas en la referida Real Orden de 18 de Febrero último.

Madrid, 25 de Junio de 1847." (22).

De acuerdo con lo dispuesto sobre buques de vela, el Banco procedió inmediatamente a la compra de nuevas unidades en los Astilleros españoles de "Braña Abella y Cía." del Ferrol, y en los de "Manzanedo y Casares" (23):

-En 1847, construyó la fragata de 319 Tons. "Unión", que pasaría a desempeñar los viajes del "Correo Marítimo Número Uno" (24).

-En 1848, compró la corbeta de 291 Tons. "Paquete de La Coruña", como "Correo Marítimo Número Seis" (25), la antigua fragata de 160 Tons. "Nuestra Señora del Carmen", como "Correo Marítimo Número Siete" (26), y el antiguo bergantín de 147 Tons. "Joven Emilio" (o simplemente "Emilio") como "Correo Marítimo Número Ocho" (27). Para una expedición extraordinaria utilizará un "Correo Marítimo Número Nueve" en el viaje del 28 de Mayo de ese año, éste era un antiguo bergantín de 160 Tons.

-En 1849 completaría la lista de correos a vela con cuatro nuevas fragatas: el primer grupo, la "Hispano Cubana" de 338 Tons. "Correo Marítimo Número Dos" (28), y la "Fomento", que sería "Correo Marítimo Número Dos", de igual tonelaje; y un segundo grupo, a finales de Octubre y principios de Noviembre,

(22) Real Orden estableciendo las nuevas Bases del Contrato con el Banco Español de Ultramar para el servicio de Correos Maritimos entre la Peninsula y las Antillas. Madrid, 25 de Junio de 1847. A.G.I. Ultramar, 854.

(23) Carta de Don Antonio Jordá, Director del Banco Español de Ultramar al Ministro de la Gobernación. Madrid, 24 de Enero de 1848. A.G.I. Ultramar, 854.

(24) Entró en Cádiz, en su primer viaje, el 25 de Noviembre procedente de La Coruña, coñ un flete de patatas. Había sido construida en Ferrol. Vid. Parte Oficial de Vigía. Cádiz, 25 de Noviembre de 1847. B.T.G.

(25) Salió de Cádiz, en su primer viaje, el 11 de Enero de 1848. Vid. Parte Oficial de Vigía. Cádiz, 24 de Diciembre de 1847 y del 11 de Enero de 1848. B.T.G.

(26) Anunciada para su salida como fragata habilitada de Correos para el viaje de Febrero de 1848. Salió de Cádiz, en su primer viaje, el 12 de Febrero de 1848 ya con el nuevo nombre de Correo Maritimo Número Siete. Vid. Parte Oficial de Vigía. Cádiz, 18 de Enero de 1848 y del 12 de Febrero de 1848. B.T.G.

(27) Anunciada para su salida como bergantín habilitado de Correos para el viaje de Marzo de 1848. Salió de Cádiz, en su primer viaje, el 10 de Marzo de 1848 ya con el nuevo nombre de Correo Maritino Nímero Ocho. Vid. Parte Oficial de Vigía. Cádiz, 19 de Febrero de 1848 $y$ del 10 de Marzo de 1848. B.T.G.

(28) Entró en Cádiz, en su primer viaje, el 13 de Febrero de 1849 procedente de La Coruña, en lastre. Había sido construida en Ferrol. Salió como Gorreo Marítimo Número Dos el 11 de Marzo de 1849. Vid. Parte Oficial de Vigia. Cädiz, 13 de Febrero de 1849, 11 de Marzo de 1849. B.T.G. 
constituido por la "Emilia Luchana" y "Francisco de Paula - Ultramar" de 345 toneladas (29).

Pero nada se había realizado con respecto a la construcción de buques a vapor. El plazo finalizaba en Junio de 1848, y en Enero de ese año Antonio Jordá, Director del Banco Español de Ultramar presenta al Ministro de la Gobernación un informe en el que solicitaba la ampliación de la prórroga en la construcción de los buques a vapor, para ello presentaba el primer proyecto de construcción de buque correo a vapor, en España.(30) Son los Astilleros Vinent y Vives de Cádiz los que avalan este temprano proyecto de 1848 , del cual se conserva parte de su planimetría en el Archivo General de Indias (31), aunque haya sido, hasta ahora, ignorado por los estudios relativos a la transición del buque de vela al de vapor. El presupuesto presentado puede considerarse como la primera aproximación al que podría haber sido el pionero de los vapores transatlánticos españoles y nos permite una idea bastante completa del costo de este tipo de embarcaciones y el porcentaje que representaba la nueva maquinaria: más del doble del costo de la madera empleada (Véase en el Gráfico 3 el porcentaje de las diferentes partidas de construcción).

\section{EL ABANDONO DEL PROYECTO DE VAPORES POR PARTE DE LA EMPRE- SA DE CORREOS MARITIMOS (1849)}

Desde que el 25 de Junio de 1847, fecha en la cual el Banco Español de Ultramar había sido instado por el Gobierno a establecer una línea de vaporescorreos, hasta finales del mes de Diciembre de 1848, los gestores de la nueva Empresa de Correos Marítimos habían ido dilatando los plazos de adquisición de los nuevos buques en virtud de un hipotético patriotismo que los obligaba a realizar la construcción en unos Astilleros españoles. El incumplimiento en la puntualidad del servicio originó las primeras desaveniencias con las autoridades habaneras, que pasó de una actitud dialogante y siempre a la defensiva, a situarse

(29) La fragata "Emilia Luchana" entró el 30 de Octubre y la "Francisco de Paula" el 1 de Noviembre. Vid. Parte Oficial de Vigia. Cádiz, 30 de Octubre de 1849, 1 de Noviembre de 1849. B.T.G.

(30) Carta de Don Antonio Jordá, Director del Banco Español de Ultramar al Ministro de la Gobernación. Madrid, 24 de Enero de 1848. A.G.I. Ultramar, 854:

"Nosotros renunciamos a esta diferencia favorable por honra de nuestro país [se refiere a la diferencia de precio entre comprar el vapor en el extranjero y llevar a cabo la construcción en Cádiz]; renuncie el Gobiemo a una insignificante prioridad de tiempo [prórroga del plazo de adquisición de vapores en Junio] y entre ambos habremos hecho un servicio util, honroso y eminentemente nacional. Entre seguir rindiendo parias a los estrangeros o gastar unos cuantos miles de reales más ni un momento hemos vacilado nosotros; entre esperar unos cuantos meses más y tener vapores españoles tampoco creemos que vacilará V.E. Es tan importante y trascendente para el bien del país la medida que proponemos, implica tal pensamiento de gobieno y de nacionalidad que no tememos deje V.E. de acogerla con la ilustración de su patriotismo; 'y mucho menos si se atiende a que de las dos concesiones que su realización exige nos toca a nosotros la más importante, la relativa a dinero".

(31) Idem. A.G.I. Ultramar, 854. 
abiertamente contraria a la Empresa. Así el Capitán General de la Isla se pronunció el 8 de Diciembre de 1848 en el sentido de la urgente necesidad de establecer ya los buques vapores. Se añadía a este argumento el carácter estratégico de las que debían ser las nuevas comunicaciones, ante la facilidad con que se desarrollaban, precisamente, los vapores con los vecinos Estados Unidos:

"El sistema actual de comunicaciones por buques de vela aleja tanto más a esta Antilla de la Metrópoli cuanto más la acercan al Continente Americano las diferentes líneas de vapores establecidas entre sus puertos y el de La Habana. Y esto es verdad no sólo geográficamente sino también moralmente" (32).

se llega, incluso, a asociar el sistema de vapores con consideraciones independentistas:

"La facilidad, comodidad y baratura de las comunicaciones multiplican las relaciones existentes y crean otras nuevas y si consideramos que el libre sistema económico con que nuestro gobierno rige a esta Ysla, si atendemos a la protección y liberalidad casi sin ejemplo que en ella disfrutan los estrangeros si como observa S.E. con mucha exactitud en la vecina República brotan las semillas de perdición para estas posesiones (...) los jóvenes que desde hace algunos años van a recibir su instrucción y los primeros elementos de una educación enteramente agena a nuestra religión, nuestra lengua, nuestras costumbres y habitos precisamente hija de instituciones e intereses distintos a los nuestros (...) que bien pudieran llegar aquí los abundantes gérmenes de disolución con que los enemigos de España han procurado fomentar en América el espíritu de la rebelión" (33).

Esta carta coincidía también con el Informe negativo de los peritos de Marina del Apostadero de La Habana sobre los nuevos barcos adquiridos por la Empresa en Ferrol. En este cúmulo de circunstancias el Director del Banco de Fomento y Ultramar manifestaba en carta fechada once días después, la absoluta imposibilidad en que se encontraba de poder adquirir los nuevos buques a vapor. De esta forma se produce la definitiva renuncia por parte civil a la adquisición de los que hubieran sido los primeros buques a vapor transoceánicos de la historia de la Marina Mercante española. Para el Banco de Fomento y Ultramar la única posibilidad era mantener e incluso ampliar (hasta dieciocho viajes) la línea con buques veleros. Consultado el Consejo Real el 21 de Febrero de 1849, éste no aceptó la proposición del Banco y decidió llevar a cabo los trámites de rescisión del contrato firmado dos años antes, primero con Manuel Villota y luego con Antonio Jordá.

En realidad el proyecto de vapores propuesto por el Gobierno de Madrid era difícilmente realizable en estos años por una empresa civil. El Comandante de Marina, en un Informe, aludido con anterioridad, contempla el problema como "un pensamiento de gobierno". En principio se percata de esta imposibilidad civil:

(32) Informe de la Comisión encargada para la reforma del sistema de Correos Maritimos por la Junta de Fomento de Agricultura y Comercio de La Habana al Capitán General. La Habana, 12 de Marzo de 1849. A.G.I. Ultramar, 854.

(33) Idem. 
"Además me consta que varias empresas han hecho proposiciones al Gobierno con el objeto de establecer líneas de vapores entre España y las Antillas y a pesar de la protección que el mismo Gobierno estuvo siempre dispuesto a concederles ninguna pasó de los preliminares" (34).

y posteriormente propone una financiación estatal de estos proyectos como única salida que desbloquee la actual situación:

"Conocerá que es imposible que tantas empresas se sostengan solamente con los pasageros y correspondencia y desde luego se descubre un pensamiento de gobierno el cual sostienen pagando con profusión el servicio de conducir la correspondencia o bien con primas con que en casos dados auguran las empresas como ya sucedió con la existente Inglesa" (35).

La posibilidad de utilización de los vapores extranjeros que tocaban la Isla, como conductores de la correspondencia, no parece admisible por las autoridades militares, aunque es propuesto tanto por la Administración de Correos, como por el Tribunal de Comercio, especificando este último que irían "custodiadas las valijas por un empleado español cuando la bandera no fuese nacional" (36). Estos organismos ponían como ejemplo que Inglaterra, a pesar de tener buques vapores, no tenía recelos en enviar su correspondecia a la India y China por los vapores franceses con base en Marsella. Cualquier proyecto extranjero terminará por desecharse. En Abril de 1849 la Junta de Fomento de Cuba presente un plan para el establecimiento de vapores desde Cádiz a La Habana.

\section{EL PROYECTO DE LA JUNTA DE FOMENTO DE LA HABANA (1849)}

Como ya había hecho el Consulado en 1824, su sucesora, la Junta de Fomento, cree que en 1849 es la hora de actuar, y con los mismos mecanismos que cuando la creación de la Empresa Mercantil de Correos Marítimos de La Habana, pone en marcha una Comisión que desarrollará un plan de vapores correos.

"Los que suscriben opinan que se conseguiria [la regularidad de la línea] con el establecimiento de una línea de vapores entre Cádiz y este puerto, con escalas en Canarias y Puerto Rico con ramificaciones que partieran de los puntos extremos ora para el Mediterráneo y para el $\mathrm{N}$. de la Península, ora para el Golfo Mejicano, Centro América y Costa Firme. (...) Y en La Habana ¿qué empreśa de vapores podría hallar más seguros rendimientos que una española? ¿no viene hoy aquí la correspondencia y pasageros del Golfo Mejicano y de la América del Sur? ¿no se reunirán en Puerto Rico los de las Antillas francesas y acaso también de las dinamarquesas? ¿no es natural que esos pasageros en su mayor parte españoles, hispano-americanos y

(34) ' Informe del Comandante General de Marina al Capitän General. La Habana, 6 de Enero de 1849. A.G.I. Ultramar, 854.

(35) Idem.

(36) Informe del Tribunal de Comercio al Capitán General. La Habana, 31 de Enero de 1849. A.G.I. Ultramar, 854. 
franceses prefieran la línea española a la Inglesa o las Americanas contando con navegantes que reunen las cualidades más simpáticas y las condiciones más apreciables para la navegación?" (37).

A todos estos recursos, la Comisión añadirá el transporte de azogues de Almadén a Veracruz, en clara competencia con la Compañia de Vapores Inglesas, además de los fletes previstos con el desestanco del tabaco. A estos nuevos recursos habría que añadir los viejos ingresos de anteriores empresas de correos marítimos: la correspondencia postal y el transporte de reclutas y presidiarios. La forma de financiación, seguía también el modelo de 1824 cuando la "primera" Empresa: accionistas particulares con apoyo de capital público. Por una parte la Junta de Fomento aportaría "una suma tan fuerte como se los permitan los numerosos compromisos" (se refiere a la participación en otras sociedades como la Empresa de ferrocarriles), por otro lado, los accionistas capitalistas cubanos y por último las subvenciones que el Gobierno tuviera que aportar hasta completar los capitales iniciales de la operación de compra de los cuatro vapores de mil trescientas toneladas y cuatrocientos cincuenta caballos.

\section{LOS VAPORES DE IA ARMADA: EL "CALEDONIA" Y EL "HIBERNIA" (1850-1851)}

Es posible que el último plan presentado por la Junta de Fomento de La Habana se hubiera llevado a cabo si la Armada hubiese estado en la situación de abandono del año 1824, cuando surgió la primera sociedad mercantil de correos marítimos a partir de un grupo de hacendados y comerciantes habaneros. A pesar de que existiese una incipiente fuerza capitalista como para hacerse cargo de un posible proyecto civil (38) (cuestión a discutir), este no se llevó a cabo. La situación era otra en España, la Armada Nacional vivía en esos momentos un período de relanzamiento, consecuencia de una actuación política que se ve reflejada en la prensa gaditana:

"Notable ha sido el incremento de nuestra marina de guerra desde el año 1844, época en que empezó a fundarse la situación política creada por el partido moderado" (39).

En Enero de 1850 comienza la reedificación del Arsenal de la Carraca (40), como uno de los símbolos más importante de la renovación de la Armada. Pode-

(37) Informe de la Comisión encargada para la reforma del sistema de Correos Marítimos por la Junta de Fomento de Agricultura y Comercio de La Habana al Capitán General. La Habana, 12 de Marzo de 1849. A.G.I. Ultramar, 854.

(38) No olvidemos que en 1850 tiene lugar la constitución de la primera sociedad naviera de Antonio López y López (futura Cía. Trasatlántica), para un servicio de vapores entre Guantánamo y Santiago de Cuba.

(39) Editorial del periódico El Comercio. Cádiz, 21 de Octubre de 1850. Biblioteca Municipal de Cádiz (B.M.C.)

(40) Periódico El Conercio. Cädiz, 15 de Enero de 1850. B.M.C. 
mos ver en el Gráfico 4 la antigüedad de la flota de guerra española, y el crecimiento desproporcionado de los años 40 a 50 en relación a épocas anteriores. :La Marina vive, por tanto, una fase de restauración; no sólo en el número de unidades sino que de forma cualitativa puede apreciarse un incremento de los buques vapores. En 1850 la Armada dispone de dieciséis vapores (41), lo que representa casi el $30 \%$ de las unidades, pero es que además, este porcentaje supera el $70 \%$ en las nuevas construcciones ( 8 de 11 , Gráfico 5 ). No es de extrañar un nuevo comentario editorial del mismo periódico ("El Comercio" de Cádiz):

"La necesidad de restaurar nuestro poder marítimo sacando a la Armada del estado de postración a que las calamidades de los tiempos y los errores de los hombres la han reducido desde los primeros años de este siglo" (42).

En este orden de cosas, si una sociedad mercantil privada no es capaz de hacerse cargo de un servicio tan esencial para el país como el de vapores-correos con Ultramar, y si la Armada está, más que nunca, necesitada de restaurar su flota con nuevas unidades, parece que la inercia de los hechos conduce a que el 11 de Octubre de 1850 aparezca en el Parte Oficial de Vigía del Puerto de Cádiz el primer anuncio de los llamados Vapores Correos Transatlánticos:

Vapores Correos Trans-Atlánticos. El paquete de vapor de S.M.C. Caledonia, de fuerza de 450 caballos, recogerá la correspondencia pública y de oficio para CANARIAS, PUERTO RICO y LA HABANA, de la Administración de Correos el 15 del corriente, a las doce en punto de la mañana.

Nota.- Por este primer viage no admite carga ni pasageros.

Consignatarios Retortillo Hermanos (43).

Esto era una "bomba" en los planes de la Empresa de Correos, la concesión de los correos estaba pronta a finalizar.

El "Caledonia", junto al posterior "Hibernia" eran dos antiguos vapores que habían sido utilizados por la Cunard line en su primera línea transoceánica entre Inglaterra y los Estados Unidos de Norteamérica. El "Caledonia" salió en su primer viaje inaugural, sin pasajeros civiles, el miércoles 16 , conduciendo al Capitán General de la Isla de Cuba, Don José de la Concha, junto a sus familiares y su estado mayor. Iban también en este primer viaje otros contingentes militares como una compañía de Bailén o una batería de montaña (44). Ocho días después se publicaba la tabla de precios de pasaje de los nuevos vapores de la Armada,

(41) Relación de buques vapores de la Armada -a principios de 1850- y año de construcción: "Santa Isabel" (1834), "Alvaro de Bazán" (1840), "Congreso" (1840), "Península" (1842), "Andaluz" (1842), "Blasco, de Garay" (1845), "Vulcano" (1845), "Castilla" (1846), "León" (1846), "Lepanto" (1846), "Elcano" (1846), "Reina de Castilla" (1846), "Magallanes" (1846), "Don Juan de Austria" (1849), "Pizarro" (1849), "Colón" (1849), y "Pizarro" (1849), Vid: Estado de la flota de guerra española en 1850, publicado en el periódico El Comercio. Cádiz, 21 de Octubre de 1850. B.M.C.

(42) Editorial del periódico El Comercio. Cädiz, 21 de Octubre de 1850. B.M.C.

(43) Parte Oficial de Vigía. Cádiz, 11 de Octubre de 1850. B.T.G.

(44) Parte Oficial de Vigía, Cádiz, 16 de Octubréde 1850. B.T.G. 
con lo que se inicia el proceso de comercialización. El "Caledonia" llegó a La Habana el 10 de Noviembre, saliendo el 21 de vuelta para Cádiz. En su primera travesía como vapor correo español invirtió 24 días. Diez años antes cualquier bergantín podía hacer esa misma derrota en los mismo días, e incluso reducirla (45). Por eso no puede ser tan rotunda la expresión de que el vapor supuso una estabilidad en la regularidad de las comunicaciones marítimas. La velocidad del vapor era de sólo siete nudos, y ésta se incrementaba a medida que se iba consumiendo la carga combustible, llegando en el mejor de los casos a las diez millas. Además de la estancia intermedia en Funchal para el abastecimiento de carbón. Esto no quiere obviar el hecho de que en algunos viajes se redujera la travesía a menos, incluso a veinte dias, y que la prensa local gaditana hiciese de los viajes de los nuevos vapores un suceso destacable:

"Hemos oido hablar con grandes encomios de las comodidades del buque [se refiere al "Caledonia"] y del esmerado trato que reciben en él los pasajeros" (46).

En poco tiempo el Gobierno pasaría a hacerse cargo del sistema de comunicaciones marítimas liquidando el contrato con la Empresa de Correos Marítimos el 24 de Enero de 1851. En un período de diez años, la gestión de los buques correos a vapor pasarían por tres períodos, que Garay Unibaso ha establecido cronologicamente, a saber:

a) 1 de Mayo de 1851/12 de Abril de 1857: Vapores correos de la Armada en colaboración con la concesionaria "Zangroniz y Hermanos, Cía del Comercio de La Habana".

b) 12 de Mayo de 1857/12 de Mayo de 1858: Empresa de Vapores correos "Gauthier Hermanos".

c) 12 de Junio de 1858/31 de Diciembre de 1861: Empresa de Vapores correos gestionada por un consorcio de navieros catalanes bajo el nombre de "Cía. de Vapores Españoles Correos Trasatlánticos".

A partir de 1861, comienza, como sabemos, la consolidación progresiva de Antonio López como el transportista marítimo por excelencia de la segunda mitad del siglo, que con los beneplácitos tutelares del Estado consigue imponerse en las comunicaciones marítimas con las Antillas Españolas, manteniéndose incluso hasta en los años posteriores a la Independencia (47).

(45) Así puede observarse un anuncio publicado en un periódico diez años antes a la salida del vapor "Caledonia": "El bergantín español Gallo de Oro capitán Don Joaquín Gurri debe recalar a este puerto de mediados a ultimos del próximo Agosto, procedente de Barcelona y siendo buque de sobresaliente andar, como lo prueba el viage que rindió el 19 de Mayo próximo pasado desde La Habana en 23 días, se avisa a los que quieran aprovechar su salida para dicho destino..." Vid. Periódico El Tiempo. Cádiz, de 5 de Julio de 1840. B.P.C.

(46) Periódico El Comercio. Cádiz, 16 de Diciembre de 1850. B.M.C.

(47) Sobre la Compañía Trasatlántica HERNANDEZ SANDOICA, E. ha desarrollado algunos aspectos de su Tesis Doctoral (Pensamiento burgués y problemas coloniales en la España de la Restauración) en los siguientes artículos: "La Navegación a Ultramar y la acción del Estado: España, 


\section{CONCLUSION}

El problema del cambio tecnológico en las comunicaciones marítimas del Estado con Ultramar, en definitiva la introducción del buque a vapor, supone a partir de los años 1847 y 1848 un cambio considerable en la actitud del Gobierno para la que había sido hasta ese momento la Empresa concesionaria del servicio de correos: la Empresa Mercantil de Correos Marítimos. El cambio de titularidad de esta Sociedad, por una parte, y la recuperación del poder naval de la Armada aceleran este proceso. La imposibilidad de llevar a cabo un proyecto civil de buque correo a vapor, presentado en 1848 por unos astilleros gaditanos ( $\mathrm{y}$ del cual este trabajo ha dado luz), reafirma la tesis de algunos autores en el sentido de que esta transición de la vela al vapor necesitaba no sólo de un cambio tecnológico sino de una nueva estrategia empresarial. Sólo una decisiva apuesta del Gobierno por el vapor podía facilitar la lenta y costosa transición de la nueva tecnología. España, al contrario que Inglaterra no pudo llevar a cabo un proyecto civil subvencionado de línea de vapores-correos, por lo que tuvo que facultar a buques de la Armada para los cometidos postales hasta que se consolidarán las nuevas empresas marítimas a finales de los años cincuenta y muy especialmente a partir de la década de los sesenta con la naviera de Antonio López.

\section{BIBLIOGRAFIA}

BAHAMONDE MAGRO, A. [Dir.] (1993) Las Comunicaciones Marítimas en la construcción del Estado contemporáneo en España: 1700-1936. Madrid. MOPT-MA.

CASANUEVA GONZÁLEZ, F. (1990) Elementos para una Historia de la Navegación a vapor. Universidad de Cádiz. Tesis inédita. Edición electrónica.

CAYUELA FERNÁNDEZ, J.G. (1993) "El Sistema Colonial de Comunicaciones en la España del Siglo XIX". Actas del I Congreso Internacional de Comunicaciones: Las Comunicaciones entre Europa y América, 1500-1993. Madrid. MOPT-MA.

GARAY UNIBASO, F. (1987) Correos Marítimos Españoles. Bilbao. Mensajero.

GUERRA AGUIAR, J.L. (1983) Historia Postal de Cuba. Madrid. Laiz.

HERNÁNDEZ MOLINA, R. (1991) Antecedentes Históricos de la Propulsión Mecánica o el Ingenio de Blasco de Garay. Universidad de Cádiz. Tesis inédita. Imprenta.

HERNÁNDEZ SANDOICA, E. (1982) Pensamiento burgués y problemas coloniales en la España de la Restauración, 1875/1887. Universidad Complutense, Madrid. Tesis reprografiada.

PASTOR PRIETO, S. (1982) El Transporte Marítimo en España. Universidad Complutense, Madrid. Tesis inédita.

siglo XIX". Estudios de Historia Social, 1988, núms. 44/47 (Enero-Diciembre) pp. 105-113: "El transporte por mar y la acción del Estado en la España del siglo XIX: Cuba y Filipinas en la concurrencia naviera por la subvención oficial". Hispania, 1987, núm. 167 t.XLVII (SeptiembreDiciembre) pp. 977-999; "Transporte Marítimo y horizonte ultramarino en la España del siglo XIX: la naviera Antonio López y el servicio de correos a las Antillas". Cuadernos de Historia Contemporánea de la Universidad Comphutense de Madrid, 1988, núm. 10 pp.45-70; y "La Compañía Trasatlántica Española: una dimensión ultramarina del capitalismo español". Revista de Historia Contemporánea de la Iniversidad del Paús Vasco, 1989, núm. 2 pp. 119-137. 
PINIELLA CORBACHO, F. (1995) La Empresa Mercantil de Correos Marítimos de La Habana (1827-1851): Aproximación a los Usos Náuticos. Universidad de Cádiz.

VALDALISO GAGO, J.M. (1992) "La Transición de la Vela al Vapor en la Flota Mercante Española: Cambio Técnico y Estrategia Empresarial". Revista de Historia Económica. Año X, nº̂1.

\author{
ANEXO: GRAFICOS
}

GRAFICO 1 Tipología de las embarcaciones en el puerto de Cádiz
durante el año 1850

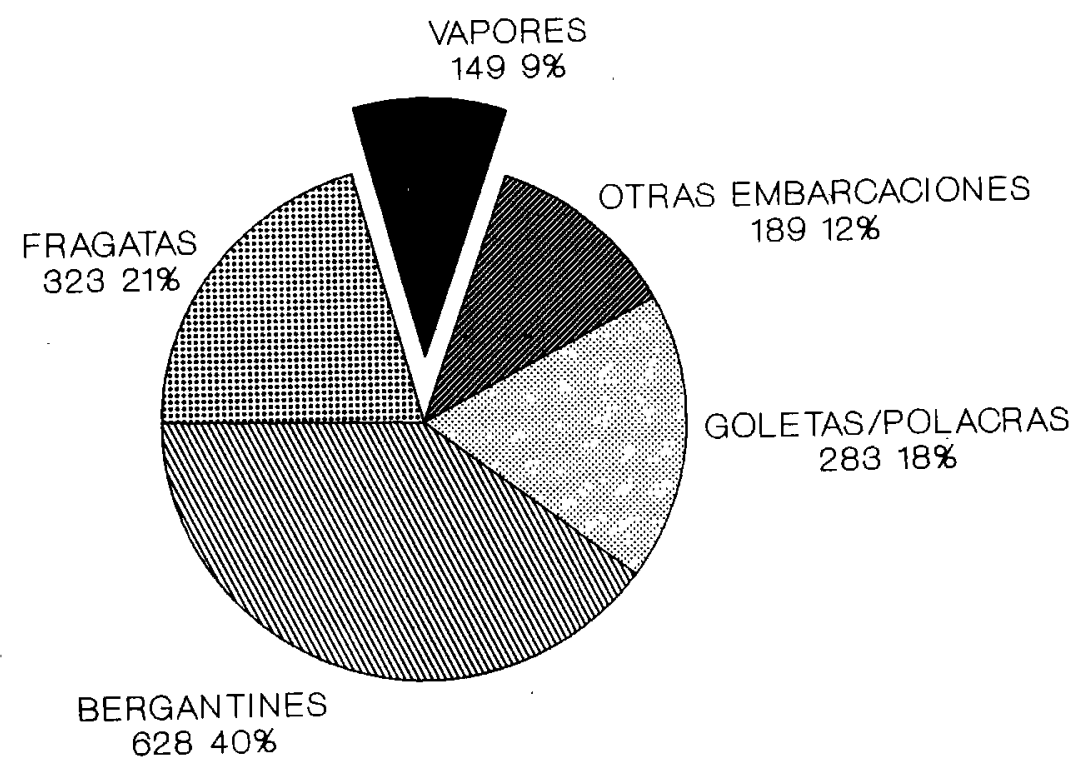

Elaboración del gráfico a partir de los datos del Parte Oficial de Vigía, Cádiz 1850. B.T.G. 
GRAFICO 2

Procedencia de los vapores entrados en el Puerto de Cádiz en el año 1850

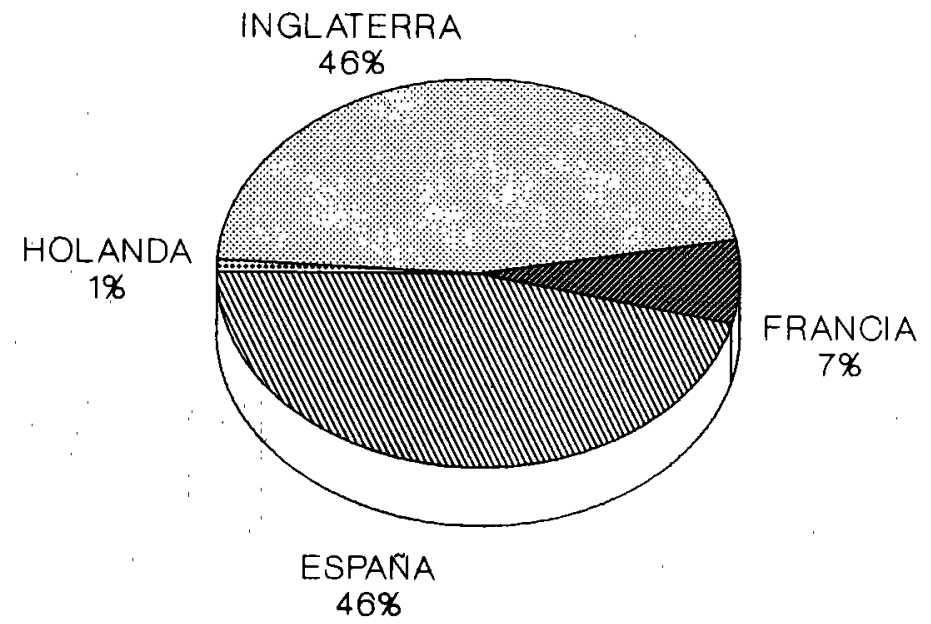

Elaboración del gráfico a partir de los datos del Parte Oficial de Vigía, Cádiz 1850. B.T.G..

\section{GRAFICO 3}

Presentación proporcional de las diferentes partidas del presupuesto para la construcción del primer buque correo a vapor (Cádiz 1848)

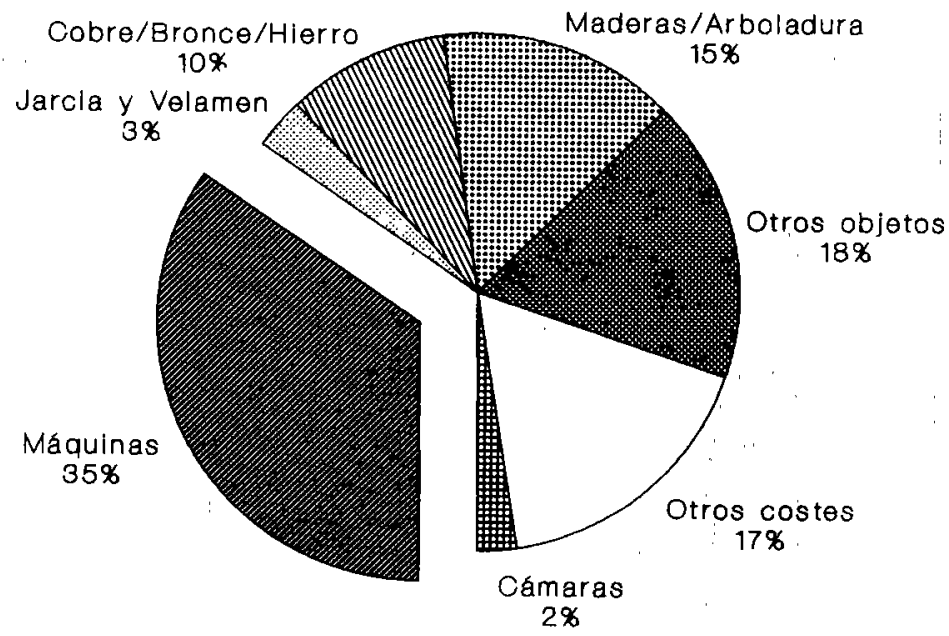

Elaboración del gráfico a partir del presupuesto para la construcción del primer buque correo a vapor, en: Carta de Don Antonio Jordá, Director del Banco Español de Ultramar al Ministro de Gobernación. Madrid, 24 de Enero de 1848. A.G.I: Ultramar, 854. 
GRAFICO 4

Antigüedad de la Flota de la Armada Española en 1850

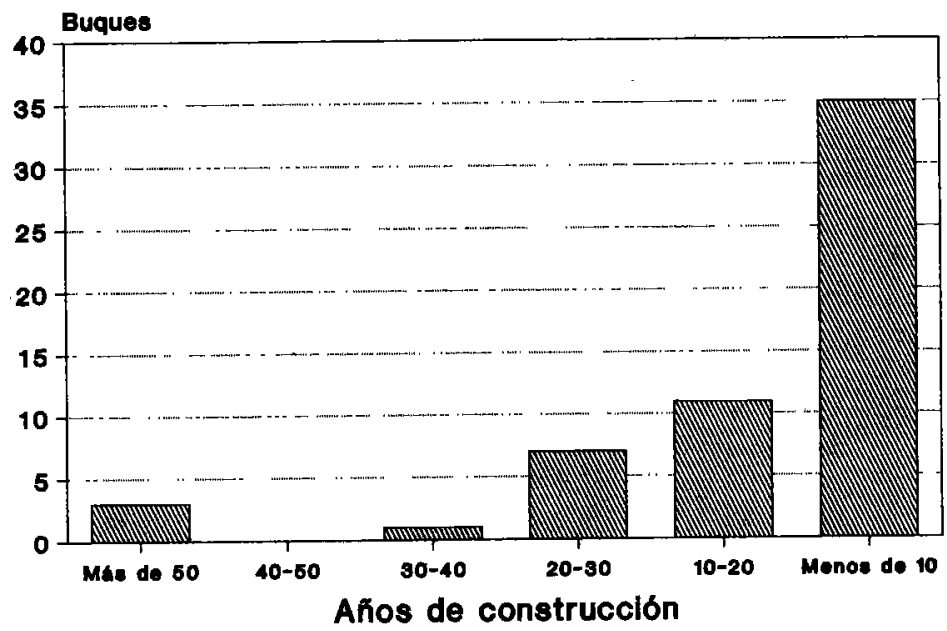

Elaboración a partir de los datos de la editorial de El Comercio de Cádiz, 24 de Octubre de 1850. B.M.C.

\section{GRAFICO 5}

Proporción de los vapores entre la Flota de la Armada Española en 1850, tanto en buques construidos como en proceso de construcción

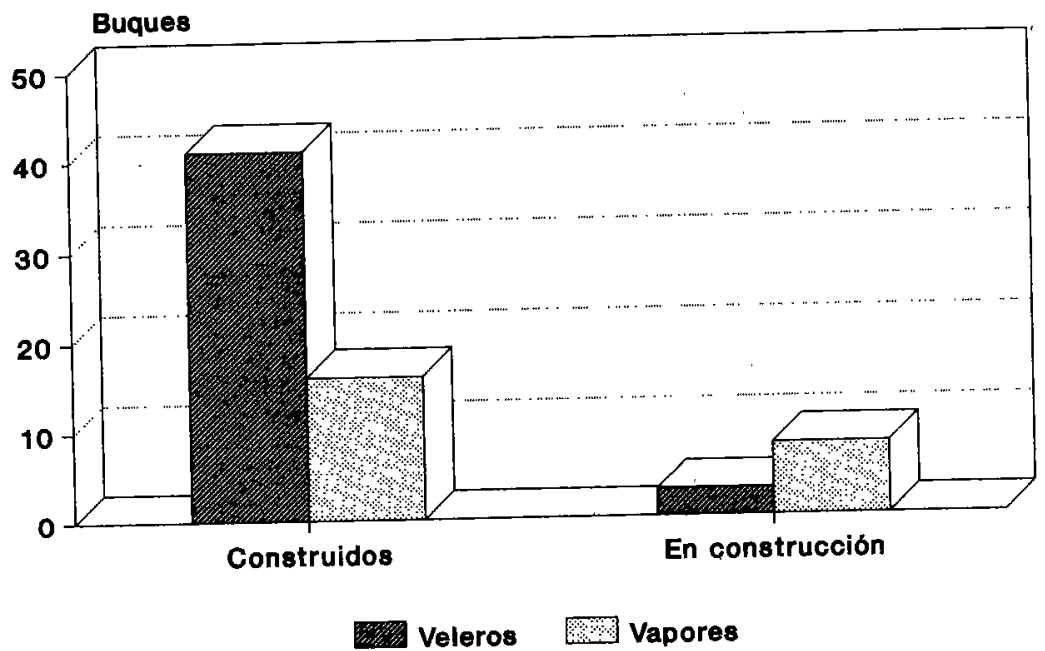

Elaboración a partir de los datos de la editorial de El Comercio de Cádiz, 24 de Octubre de 1850. B.M.C. 